\title{
然
}

Agustín Velilla Sanz*

Sara Peña Serrano*

Moisés Pérez Ruiz*

\section{EL ÉXITO DE LA EXPORTACIÓN ALIMENTARIA ESPAÑOLA A CHINA}

El mercado chino es estratégico para las exportaciones españolas de productos agroalimentarios en los próximos años. Sin embargo, no se trata de un mercado de fácil acceso, y hay que tener en cuenta numerosos factores que condicionarán nuestra oferta exportable del futuro. En este artículo se analizan algunos de estos factores y se recoge la evolución reciente de las exportaciones agroalimentarias, para concluir con algunas consideraciones de carácter general.

Palabras clave: comercio internacional, balanza comercial, productos agroalimentarios, protocolos, distribución comercial.

Clasificación JEL: F13, F32, Q17.

\section{Introducción: contexto general}

La agricultura china tiene que suministrar productos para abastecer las necesidades alimentarias de una población de más de 1.380 millones de habitantes, en torno al 20 por 100 de la población mundial. El país cuenta con una superficie total de más de 9,3 millones de kilómetros cuadrados y una superficie cultivable de 135 millones de hectáreas (aproximadamente el 13,5 por 100 del total).

La agricultura continúa teniendo un peso importante en la economía. Supone el 53 por 100

*Subdirección General de Comercio Internacional de Productos Agroalimentarios, Dirección General de Comercio Internacional e Inversiones. Secretaría de Estado de Comercio.

Versión de enero de 2018.

Los autores agradecen la información facilitada por la Oficina Económica y Comercial en Pekín. de la actividad del sector primario y emplea en torno al 28 por 100 de la población ocupada; sin embargo, su participación en el producto interior bruto (PIB) disminuye cada año (8,6 por 100 en 2016) y las diferencias de renta entre el mundo rural y el urbano aumentan. Se trata de un sector de carácter tradicional, todavía intensivo en mano de obra, que está evolucionando rápidamente gracias a la mecanización agraria (Ofecome en Pekín, 2017).

Pese a que China es uno de los principales productores agrícolas a nivel mundial de algunos productos (trigo, arroz, maíz, semillas oleaginosas, productos de cerdo, aves de corral, productos de acuicultura), seguramente tendrá que seguir importando una gran cantidad de productos agroalimentarios. Por el momento, la agricultura china no está en condiciones $D$ 
de atender la demanda creciente de productos agrícolas y es un importante importador mundial en el sector agroalimentario; en particular, cubre solo el 42 por 100 de su consumo de aceites comestibles, el 50 por 100 en azúcar y el 20 por 100 en soja. Es también dependiente de productos de origen animal (especialmente lácteos). Esta situación tiene un impacto directo en los mercados mundiales de productos agrícolas. Presenta un déficit creciente en su balanza agroalimentaria; en 2015 este alcanzó los 47.000 millones de euros.

En un contexto de fuerte aumento del poder adquisitivo de la población, la agricultura china tiene que responder a una creciente demanda de alimentos y a los cambios en los hábitos alimenticios de los consumidores, que exigen mayor variedad, calidad e inocuidad de los alimentos. Esto se observa, por ejemplo, en el consumo de carne y productos lácteos en los últimos años.

Por otra parte, las cadenas de distribución agroalimentaria también están en pleno desarrollo, respaldadas por estructuras gubernamentales (principalmente granjas estatales) o privadas (especialmente en el sector porcino). Las cadenas de distribución más importantes son las autóctonas chinas y algunos grupos extranjeros, con un gran desarrollo de venta online a través de plataformas de comercio electrónico.

En relación con la política agrícola, el XIII Plan Quinquenal (2016-2020) está encaminado a modernizar el sector agrícola, mediante su mecanización, a promover el desarrollo de las operaciones de escala media para incrementar la productividad, a profundizar en la reforma de los derechos contractuales sobre la tierra y de las políticas de financiación en las zonas rurales, a proteger la calidad de las tierras de cultivo con el fin de aumentar la productividad y a asegurar el autoabastecimiento en cereales (por lo menos el 95 por 100) y la inocuidad de los alimentos (NDRC, 2016). Para alcanzar esos objetivos se prestará más apoyo al sector, se concederán más ventajas a los agricultores, se mejorará la política actual de subvenciones y se reformará el sistema de formación de precios para los productos agrícolas, entre otras medidas (revisión de la política comercial de China: OMC, 2016).

Por otro lado, China tiene cada vez una mayor presencia y peso en el comercio internacional. Desde su adhesión a la Organización Mundial del Comercio (OMC) en diciembre de 2001, China ha reducido sus aranceles de la nación más favorecida (NMF) y mantiene contingentes arancelarios para el trigo, el maíz, el arroz, algunas harinas de cereales, el azúcar de caña y la remolacha. Igualmente, en el ámbito bilateral, está negociando acuerdos comerciales, dando prioridad a los países vecinos con el fin de fortalecer la integración regional y garantizar un suministro de materias primas necesarias a su economía. Su asignatura pendiente sigue siendo la reticencia de las grandes economías mundiales a negociar acuerdos comerciales con China.

\section{Comercio de productos agroalimentarios}

Los principales proveedores de China, en términos de importaciones agroalimentarias, son Estados Unidos (23 por 100), del que China es el segundo mayor cliente agrícola, y Brasil (21 por 100), del que China es el primer cliente. La república asiática se ha convertido en un actor clave en la mayoría de los países exportadores de productos agrícolas de América, el sudeste de Asia u Oceanía. Europa está en una situación diferente de dependencia. 


\subsection{Comercio Unión Europea-China}

Las estadísticas de comercio exterior correspondientes al año 2016 (Cuadro 1) muestran una evolución muy favorable de las exportaciones alimentarias de la UE al mercado chino, con una cifra de 10.593,7 millones de euros, que supone un crecimiento del 23 por 100 respecto a 2015.

Este crecimiento es similar al promedio de los tres últimos años y contrasta con el descenso del 3 por 100 experimentado en 2016 por las exportaciones totales de bienes de la UE a China, que fueron de 183.000 millones de euros.

Países como EEUU, Brasil y Chile mantienen un crecimiento similar de sus exportaciones agroalimentarias. Por el contrario,

CUADRO 1

RELACIÓN DE PAÍSES DE LA UE-28 CLASIFICADOS SEGÚN SUS EXPORTACIONES ALIMENTARIAS A CHINA EN 2016 Y VARIACIÓN RESPECTO AL AÑO PRECEDENTE

(Valor en millones de euros)

\begin{tabular}{|l|c|c|}
\hline \multicolumn{1}{|c|}{ Estados miembros } & $\begin{array}{c}\text { Exportación } \\
\text { alimentaria } \\
\text { en 2016 }\end{array}$ & $\begin{array}{c}\text { Porcentaje } \\
\text { variación } \\
\text { respecto a 2015 }\end{array}$ \\
\hline Francia & $2.421,3$ & +15 \\
Alemania & $1.996,2$ & +30 \\
Países Bajos & $1.682,3$ & +21 \\
España & $1.169,5$ & +48 \\
Dinamarca & 970,4 & +47 \\
Irlanda & 728,2 & +6 \\
Italia & 466,6 & -3 \\
Reino Unido & 407,1 & +9 \\
Bélgica & 233,6 & +33 \\
Polonia & 112,7 & -25 \\
Resto EEMM & 415,8 & +16 \\
Total alimentario & $\mathbf{1 0 . 5 9 3 , 7}$ & $\mathbf{+ 2 3}$ \\
\hline Total exportado UE-28 & $\mathbf{1 8 3 . 1 4 8 , 0}$ & $-\mathbf{3}$ \\
a China en 2016 & & - \\
\hline Porcentaje alimentario & $\mathbf{5 , 8}$ & \\
\hline sobre total exportación & & \\
\hline Fuente: GTA, estadísticas chinas y datos elaborados por la Oficina \\
Comercial de Pekín.
\end{tabular}

Australia y Nueva Zelanda solo crecieron un dígito debido a los bajos precios mundiales de los lácteos.

Los últimos datos de comercio de la UE-28 (octubre de 2016-octubre de 2017) muestran que el 8,7 por 100 del total de las exportaciones de la UE de productos agroalimentarios se destinan a China. Es el segundo destino de las exportaciones de la UE, detrás de EEUU, con un valor de 11.889 millones de euros, lo que representa un incremento del 6,5 por 100 con respecto al mismo periodo del año anterior. Por su parte, China ocupa el quinto puesto del origen de las importaciones de la UE, con 5.370 millones de euros en el periodo octubre de 2016-octubre de 2017, con un incremento del 5,4 por 100 respecto al año anterior (Comisión Europea, 2017).

\subsection{Comercio España-China}

Las exportaciones alimentarias españolas a China crecieron durante 2016 un 48 por 100, que es el mayor incremento de la UE-28, doblando el de Francia, Alemania y Países Bajos y siendo el segundo a nivel mundial, detrás de Brasil.

En el periodo 2008-2016 nuestras exportaciones alimentarias a China se han multiplicado por 17 , pasando de 80 a superar los 1.000 millones de euros. España, con estos datos, se sitúa en el puesto $n . \stackrel{0}{11}$ de los países proveedores de alimentos a China, mejorando cinco posiciones respecto al puesto que ocupaba hace cuatro años.

A diferencia de lo que ocurre en la balanza comercial de bienes, en el caso del sector agroalimentario, desde el año 2015, la balanza presenta un superávit para España. Las exportaciones españolas del sector agroalimentario $\triangleright$ 


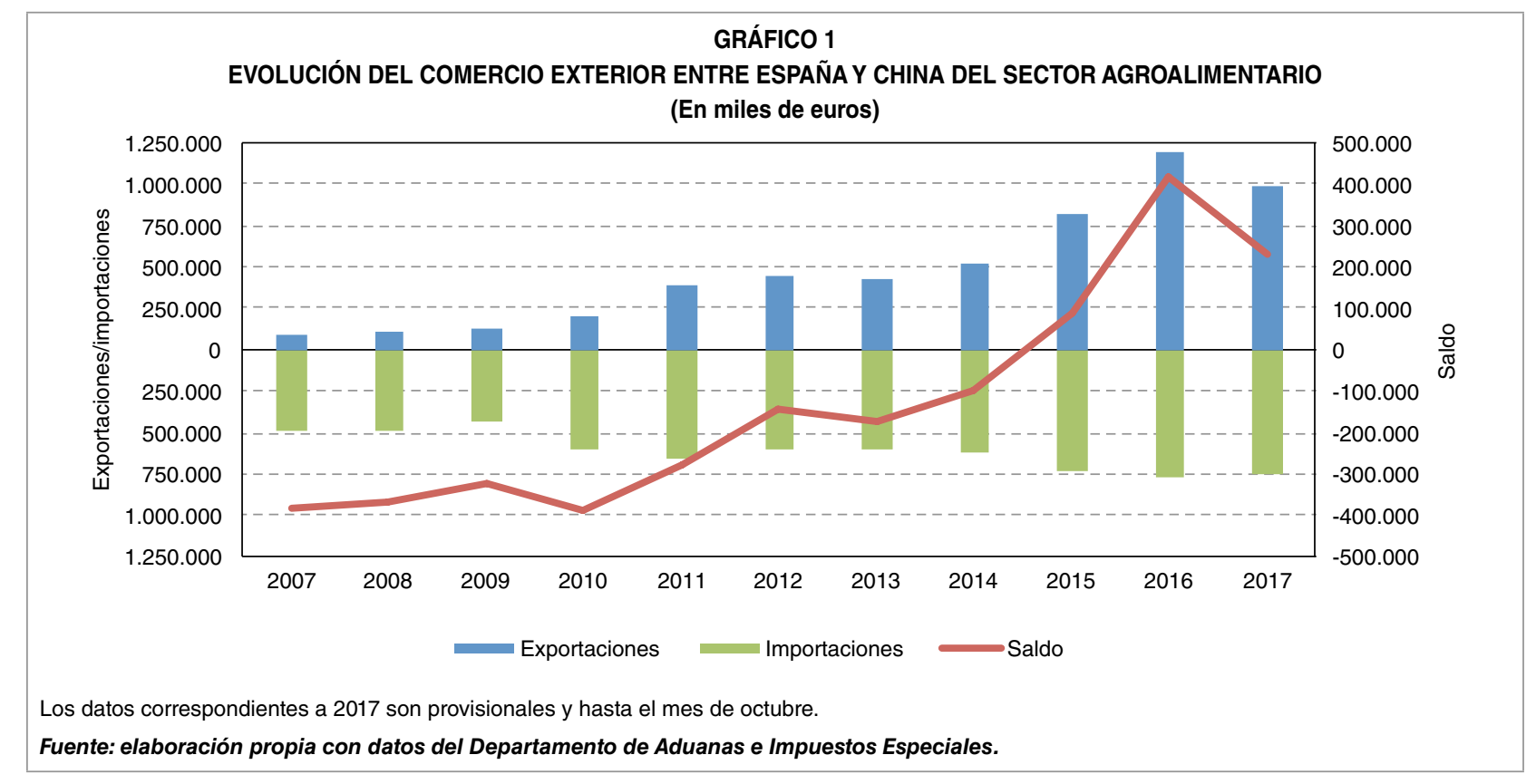

en el año 2016 representaron aproximadamente el 24,5 por 100 del total agroalimentario exportado por España, llegando a 1.196 millones de euros y a un volumen de 770.400 toneladas. Las importaciones alcanzaron un valor de 779 millones de euros y 331.419 toneladas (aproximadamente el 3,3 por 100 del total importado por España), con lo que la balanza bilateral agroalimentaria presentó un saldo positivo de 416 millones de euros.

En los nueve primeros meses de 2017 (según datos de las aduanas chinas suministrados por la Oficina Comercial en Pekín), se consolidan las cifras de comercio de 2016. Las cifras de ventas a la República Popular China alcanzan hasta el tercer trimestre los 885 millones de euros, lo que supone un crecimiento en valor del 0,2 por 100 respecto al año precedente.

En el Gráfico 1 se muestra la evolución de los últimos años.

Por orden de importancia, el sector más representativo es el cárnico, gracias a las exportaciones de porcino, seguido del sector de vinos y bebidas, grasas y aceites, productos agrarios transformados y productos de la pesca. En cuanto a las importaciones, los productos de la pesca suponen casi el 50 por 100 de las importaciones procedentes de China, seguido de los productos agrarios transformados, semillas, oleaginosas, mandioca y forraje y conservas vegetales. En la Cuadro 2 se pueden ver los datos de comercio exterior, desagregados por sectores.

En los últimos años (Gráfico 2), el sector que más ha aumentado sus exportaciones es el sector cárnico. Los otros cuatro sectores en importancia (vinos y bebidas, grasas y aceites, otros productos de los capítulos 5 y 14, y PAT -productos agrarios transformados-) también continúan mostrando una tendencia positiva.

El grueso de las exportaciones agroalimentarias se corresponde con las exportaciones del sector cárnico y en particular con las de porcino. El cierre del mercado ruso explica, en gran medida, el espectacular crecimiento que hemos tenido. En 2016, España se ha convertido en el tercer exportador de carne y despojos de porcino a China, solamente por detrás de Alemania y EEUU, y adelantando a Dinamarca y Canadá. $D$ 
CUADRO 2

COMERCIO EXTERIOR ESPAÑA-CHINA POR SECTORES, AÑO 2016

\begin{tabular}{|c|c|c|c|c|c|}
\hline \multirow{2}{*}{ Sector arancelario } & \multicolumn{2}{|c|}{ Exportaciones } & \multicolumn{2}{|c|}{ Importaciones } & \multirow{2}{*}{$\begin{array}{c}\text { Saldo } \\
\text { Miles de euros }\end{array}$} \\
\hline & Miles de euros & Toneladas & Miles de euros & Toneladas & \\
\hline Sectores cárnicos & 633.982 & 388.432 & 1.979 & 301 & 632.003 \\
\hline Vinos y bebidas & 202.823 & 147.999 & 2.054 & 2.067 & 200.770 \\
\hline Grasas y aceites & 142.515 & 60.547 & 6.027 & 1.979 & 136.488 \\
\hline Otros productos agrícolas, caps. 5 y 14 & 62.419 & 42.939 & 33.456 & 11.253 & 28.963 \\
\hline Productos agrarios transformados & 54.306 & 14.355 & 129.849 & 63.495 & -75.542 \\
\hline Pesca & 33.045 & 9.209 & 357.193 & 116.645 & -324.147 \\
\hline Lácteos & 19.678 & 16.262 & - & - & 19.678 \\
\hline Frutas & 17.466 & 14.980 & 8.430 & 2.284 & 9.036 \\
\hline Semillas, oleaginosas, mandioca y forraje & 14.391 & 64.787 & 95.293 & 49.495 & -80.901 \\
\hline Conservas vegetales & 7.566 & 5.932 & 77.695 & 41.902 & -70.129 \\
\hline Industrias alimentarias y piensos & 5.671 & 4.072 & 11.622 & 12.921 & -5.951 \\
\hline Flores y plantas & 1.010 & 522 & 883 & 319 & 127 \\
\hline Café, té, cacao y azúcar & 782 & 217 & 18.706 & 7.962 & -17.924 \\
\hline Hortalizas y legumbres & 91 & 111 & 35.824 & 20.378 & -35.733 \\
\hline Cereales y productos de molinera & 17 & 37 & 551 & 401 & -534 \\
\hline Tabaco & 1 & - & 95 & 17 & -94 \\
\hline Total general & 1.195 .764 & 770.401 & 779.655 & 331.419 & 416.109 \\
\hline
\end{tabular}

En el año 2016 se exportó carne y productos cárnicos por valor de 634 millones de euros y un volumen de 388.432 toneladas. En el Gráfico 2 puede observarse el incremento de las exportaciones del sector cárnico en estos últimos años. El 97 por 100 del total del sector cárnico lo representa el porcino. Sin embargo, las exportaciones a China han caído en el primer semestre de 2017 y se espera que no superen las del año anterior.

El segundo subsector más importante en las exportaciones españolas a China es el de vinos y bebidas: se exportó en 2016 por valor de 203 millones de euros. Las exportaciones más importantes son de vino, seguidas de cerveza y mosto. En 2016 las exportaciones de vino alcanzaron 114,2 millones de euros, destacando los envíos de vinos embotellados con denominación de origen. En el caso de las cervezas, se exportaron por valor de 46 millones de euros, siendo la embotellada el producto más relevante. Las exportaciones de mosto son mucho menores que las de los principales productos: se exportó por valor de casi 9 millones de euros en 2016.

En el año 2017 es previsible que se superen los valores de exportaciones con respecto a 2016. En particular, en el caso del vino, ya con los datos de 2017 hasta octubre, se habían exportado por valor de 144 millones de euros, cifra que supera las exportaciones de todo 2016. Este aumento es gracias, entre otras, a las exportaciones de vinos a granel, que han crecido significativamente en los últimos meses.

Dentro del subsector de grasas y aceites, se observa una evolución positiva en los últimos años de las exportaciones. En 2016 el valor de las exportaciones fue de 142 millones de euros y un volumen de 60.547 toneladas, con el aceite de oliva como el producto más exportado, $D$ 


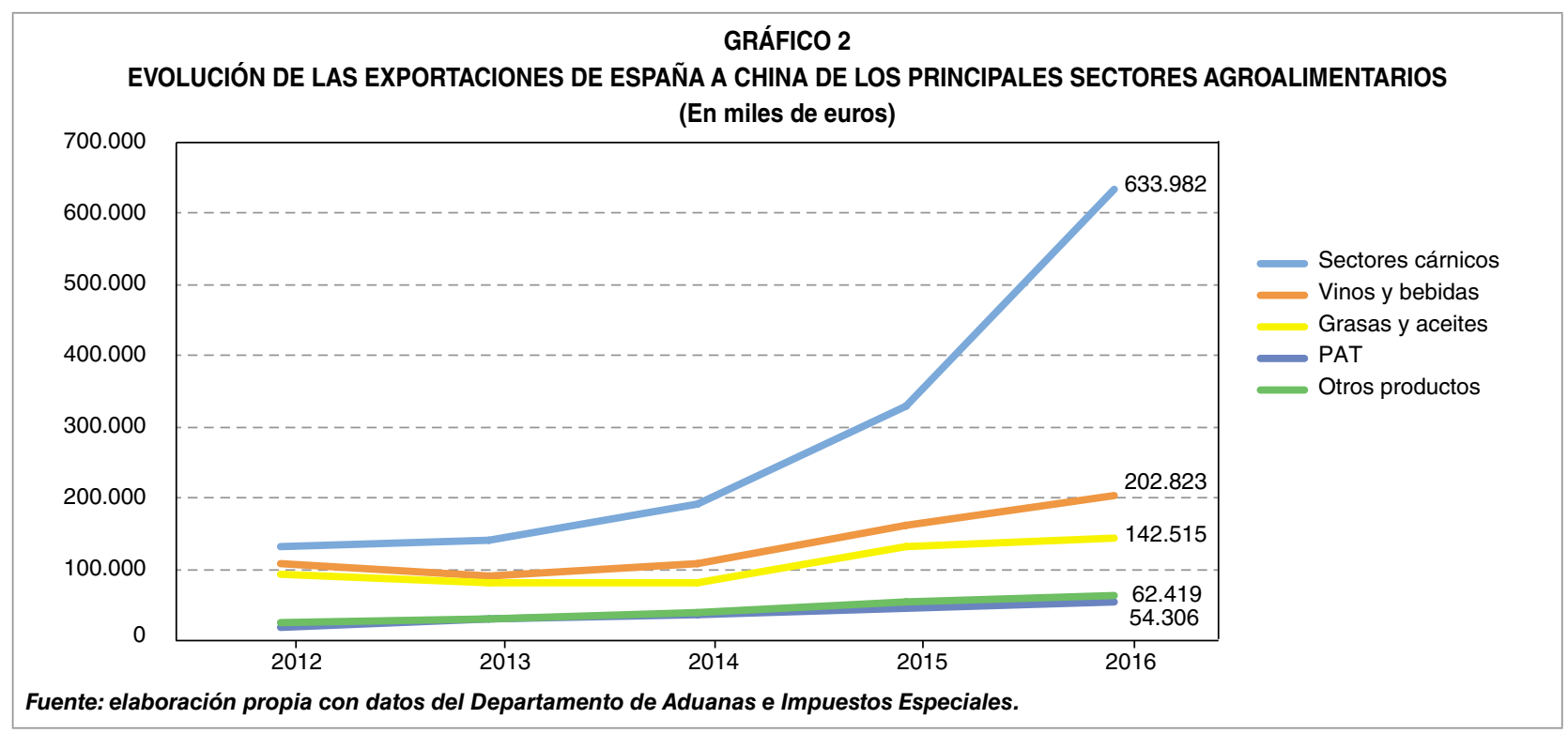

con un valor de las exportaciones de 133 millones de euros y 27.695 toneladas en volumen. El 83 por 100 de las exportaciones de aceite de oliva son de aceite de oliva virgen.

En cuanto a "otros productos agrícolas», este sector comprende los productos del capítulo 5 del sistema armonizado (los demás productos de origen animal no expresados ni comprendidos en otra parte) y el capítulo 14 (materiales trenzables y demás productos de origen vegetal). Se exportó en el año 2016 por valor de 62,4 millones de euros, siendo el cuarto sector más importante de la exportación española. El año 2017 superará con creces las exportaciones del año anterior, ya que, según los datos disponibles hasta octubre, las exportaciones supusieron 76 millones de euros.

Del conjunto de partidas incluidas en el sector de productos agrícolas sin clasificar, principalmente se exportan tripas, vejigas y estómagos de animales, enteros o en trozos, frescos, refrigerados, congelados, salados o en salmuera, secos o ahumados por valor de 32 millones de euros y un volumen de 11.554 toneladas; y huesos córneos, por valor de 27 millones de euros y un volumen de 30.993 toneladas.

\section{Algunos aspectos a considerar en la evolución futura del comercio agroalimentario con China}

En la actualidad existen algunas incertidumbres que se ciernen en el comercio internacional con China, que condicionarán por ende las exportaciones españolas a este destino. Sin ánimo de ser exhaustivo, analizamos algunas de ellas.

\section{1. ¿Podrán los planes del Gobierno chino afectar a las importaciones?}

Los distintos planes de desarrollo agrícola ${ }^{1}$ han incrementado la producción agrícola en China, aunque se está lejos de alcanzar el $\triangleright$

1 En los últimos años, destacan el XIII Plan Quinquenal, el Plan Nacional de Seguridad Alimentaria y el Plan para la producción de porcino. 
deseado autoabastecimiento. Varios son los factores que señala la OCDE-FAO sobre las perspectivas del sector agrícola en China:

1) El crecimiento económico previsto en los próximos años, aunque será menor, seguirá estimulando la demanda.

2) Los cambios demográficos y el éxodo del medio rural a urbano, la propiedad de la tierra, el aumento de la población urbana que conlleva un mayor consumo de carne, lácteos y pescado.

3) La reducción de la tierra cultivable, la gestión del agua y la contaminación de suelo agrícola.

4) Los cambios en las cadenas de comercialización de alimentos de mayor calidad y seguros, que implican al sector primario.

5) Políticas gubernamentales de subsidios y precios mínimos a los productores (OCDE-FAO, 2017).

Pese a que los cereales siguen siendo el principal cultivo (68 por 100 de la superficie), se observa una tendencia de cambio hacia otros cultivos más rentables como frutas, flores, té y café, cuya demanda muchas veces aumenta por encima de la oferta, incrementando los precios.

La ganadería sigue en importancia a la agricultura, con el 28 por 100 del valor añadido del sector primario. La superficie de pastos es de unos 220 millones de hectáreas, localizadas, principalmente, en Mongolia Interior, Tíbet y Xinjiang. La cabaña de porcino (China es el mayor productor mundial) está criada en pequeñas explotaciones por todo el país, al igual que la cría de aves de corral. En 2016 la producción ganadera cayó un 2,4 por 100 respecto al año anterior. La cabaña de bovino en 2016 se redujo a 107 millones de cabezas y la de ovino, a 301 millones de cabezas. La producción de carne en 2016 alcanzó 85 millones de toneladas, un 1,2 por 100 menos que el año anterior, correspondiendo 53 millones de toneladas a carne de cerdo, 7,17 millones de toneladas a vacuno, 4,59 millones de toneladas a ovino y 20 millones de toneladas a carne de ave. La producción lechera en 2016 ascendió a 37 millones de toneladas.

China es el primer país pesquero del mundo, tiene recursos disponibles en sus propias aguas y flota en múltiples países de todo el mundo. En 2016 la producción del sector pesquero alcanzó los 69 millones de toneladas, de las que 15 millones corresponden a capturas marinas, 20 millones a cultivos marinos y 31 millones a cultivos de piscifactoría (Ofecome en Pekín, 2017).

En la medida en que los planes sean exitosos es previsible que el ritmo de importaciones se ralentice. En algunos sectores importantes para las exportaciones españolas es un elemento a tener en cuenta en el corto/medio plazo.

\section{2. ¿Afectará el entorno legislativo a las exportaciones?}

En el año 2015 se publicó en China la Ley de Seguridad Alimentaria con el fin de asegurar la inocuidad de los alimentos exportados al país asiático. En el marco de esta nueva legislación se establece la necesidad de un certificado armonizado para los productos alimenticios de bajo riesgo, que tiene que ser emitido por la autoridad competente del país o región exportadora.

Los productos cubiertos por este nuevo certificado, y que se encuentran incluidos en la $\triangleright$ 
notificación que hizo la Agencia de Supervisión de Calidad, Inspección y Cuarentena de China (AQSIQ) al Comité de Obstáculos Técnicos al Comercio de la Organización Mundial del Comercio (G/TBT/N/CHN/1209), abarcan la gran mayoría de productos agroalimentarios incluidos en los capítulos del 1 al 24 del sistema armonizado (OMC, 2017).

La obligatoriedad de este certificado armonizado iba a entrar en vigor inicialmente el día 1 de octubre de 2017, aunque ante la presión de los países exportadores se consiguió posponer esta fecha. El 25 de septiembre de 2017 se publicó una adenda a la notificación G/TBT/ $\mathrm{NCHN/1209}$ en la que se comunicaba que la certificación se exigirá a partir del 1 de octubre de 2019 (OMC, 2017).

Según datos de la Oficina Económica y Comercial de España en Pekín, esta medida habría afectado al 83,21 por 100 de las exportaciones agroalimentarias españolas.

En la actualidad, esta situación sigue generando incertidumbre entre los operadores económicos, tanto exportadores españoles como importadores chinos, ya que se trataría de un nuevo trámite administrativo a la entrada del país que puede suponer retrasos en el despacho aduanero una vez que el producto ya esté en los puntos de entrada de mercancías en China.

\section{3. ¿Qué disputas comerciales dificultarán los intercambios?}

Las medidas que toma China sobre la protección de su mercado interno generan distorsiones en el comercio internacional. En este sentido, los titulares de comercio de la Unión Europea, EEUU y Japón acordaron, en la Conferencia Ministerial número 11 en Buenos
Aires, el fortalecimiento de su compromiso para asegurar unas «reglas de juego equilibradas» en el marco multilateral (Lighthizer, Seko y Malmström, 2017). Es decir, que se respeten los compromisos asumidos dentro del marco de la OMC.

En particular, hay tres casos que están abiertos que afectan a los productos agroalimentarios, en los que EEUU reclama a China la aplicación de medidas dentro del marco de la OMC.

Uno afecta a los contingentes arancelarios aplicables a determinados productos agroalimentarios (DS517); otro, a la ayuda interna para los productores agropecuarios (DS511) y el tercero trata sobre las medidas en materia de derechos antidumping compensatorios sobre los productos de pollo de engorde procedentes de EEUU (DS427) (OMC, 2017).

\section{4. ¿Mejorará el acceso al mercado chino?}

Los productos agroalimentarios actualmente se enfrentan a requisitos de tipo sanitario y fitosanitario, entre otros, por la necesidad de los países de garantizar la inocuidad alimentaria de los alimentos que entran en su territorio.

En el caso de los productos de origen animal y vegetal, y por tratarse de productos generalmente considerados de riesgo, es necesaria, en muchas ocasiones, la negociación de protocolos entre los países en los que se establecen las condiciones de los productos exportables. Esto es, los productos, condiciones higiénicas, listado de establecimientos autorizados, necesidad de un certificado sanitario, etcétera. Se trata de un sistema complejo $\mathrm{y}$, además, del cumplimiento de una legislación específica exigente (Alonso Díaz, 2009). 
En la actualidad se pueden exportar carne y productos cárnicos curados de porcino, productos lácteos, productos de la pesca, animales acuáticos vivos para consumo humano y otros productos como huevos para incubar y pollitos de un día, équidos, hemoderivados de porcino y proteína hidrolizada de plumas, huevos embrionados de trucha y salmón, células y cultivos celulares, cueros y pieles de bovinos, ovinos, caprinos, forraje deshidratado, plumas lavadas, hidrolizados proteicos de porcino para alimentación animal, lana sucia y leones marinos (CEXGAN, 2018). En el caso de los productos de origen vegetal, España únicamente tiene en vigor dos protocolos, uno para la exportación de cítricos, el cual incluye naranjas, limones, mandarinas y pomelos, y otro para la exportación de fruta de hueso: melocotones, nectarinas, paraguayos y ciruelas. (Ofecome en Cantón, 2017 y MAPAMA, 2017). Asimismo, se está terminando de negociar la ampliación del protocolo de porcino, y en el caso de los productos vegetales, desde 2012 se viene negociando la apertura del mercado para uva.

En el futuro próximo se espera que se inicien las negociaciones de protocolos para la exportación de carne y productos avícolas, carne de bovino, productos cocidos de porcino, carne de ovino y caprino.

Uno de los cuellos de botella en el acceso al mercado chino es precisamente la negociación de estos protocolos de ámbito sanitario. Las autoridades chinas suelen negociar secuencialmente los protocolos y, además, el procedimiento de negociación puede durar años. Productos que podrían exportarse no están todavía autorizados a ello por la inexistencia de protocolo o porque las negociaciones no se han terminado. Este sería el caso de muchas frutas y hortalizas, carne de bovino, carne de ave, productos cocidos del porcino o carne de ovino y caprino.

Otra de las amenazas para la evolución de las exportaciones son los cierres de los mercados como consecuencia de enfermedades o plagas. En estos últimos años se pueden citar varios casos, como el bloqueo de las exportaciones procedentes de la Unión Europea, consecuencia de la encefalopatía espongiforme bovina - China reabrirá el mercado a Francia tras cerrarlo en 2001 (O'Donovan, 2018)—; el cierre de los mercados a las exportaciones españolas de origen aviar, debido al brote de influenza aviar altamente patógena en 2017 (MAPAMA, 2017); y otros casos que pueden surgir en el futuro que supondrían el cierre del mercado chino de forma repentina y retrasar su reapertura hasta que se recuperen las condiciones sanitarias. La experiencia indica que el cierre del mercado se realiza con total rapidez, una vez detectada/comunicada una enfermedad o plaga, pero que las reaperturas suelen costar mucho más.

\section{5. ¿En qué marco se desarrollarán las relaciones comerciales UE-China?}

La UE negocia con China, desde hace tiempo, un nuevo Acuerdo de Asociación y Cooperación (PCA por sus siglas en inglés), para modernizar el marco de las relaciones bilaterales UE-China y actualizar el Acuerdo de Cooperación y Comercio de 1985. En el aspecto comercial, se trata de un acuerdo no preferencial basado en la cláusula de nación más favorecida.

Aunque existen distintos foros bilaterales, como el Diálogo de Política Comercial y de Inversiones, que se reúne anualmente para tratar temas comerciales, no está por ahora $\triangleright$ 
prevista la negociación de un acuerdo de libre comercio. Desde 2013, se viene negociando un acuerdo sobre inversiones (DGTRADE, 2018) y desde 2010, sobre protección de Indicaciones Geográficas (Comisión Europea, 2018).

La protección de las Indicaciones Geográficas es de interés bilateral. En China no hay una legislación específica sobre las mencionadas Indicaciones Geográficas, la Ley de Marcas de Fábrica o de Comercio y su reglamento de aplicación, y otras leyes y reglamentos rigen su registro y protección. Actualmente, dos organismos gubernamentales participan en la labor relacionada con las Indicaciones Geográficas: la Oficina de Marcas (SAIC) y la AQSIQ/MoA.

El inicio de la cooperación con las autoridades chinas para el reconocimiento y protección mutuos de las Indicaciones Geográficas de China y la UE surgió con el Proyecto «10 + 10», por lo que diez Indicaciones Geográficas de cada una de las partes eran protegidas en la otra. Las Indicaciones Geográficas españolas de aceite de oliva Sierra Mágina y Priego de Córdoba se incluyeron de este proyecto.

En 2013 la UE y China acordaron una nueva negociación en dos fases, con un máximo de cien Indicaciones Geográficas por cada parte en la primera fase, y las restantes de las listas intercambiadas (162 en el caso de la UE) en los años siguientes. Por el momento se ha hecho un preanálisis de la lista de 100 Indicaciones Geográficas y continúan las negociaciones.

En el ámbito de la agricultura, el mantenimiento de las buenas relaciones entre la UE y China es una prioridad para la Comisión, como así se refleja en la misión de alto nivel de mayo de 2018 en la que el comisario de Agricultura, Phil Hogan, acompañado de representantes de empresas líderes del sector agrícola europeas, tiene previsto visitar Shanghai y Shenzen, aprovechando la inauguración de la feria SIAL en Shanghai (Comisión Europea, 2018).

\section{6. ¿Podremos beneficiarnos de las nuevas rutas entre China y España?}

En la actualidad, y gracias a la construcción del Canal de Suez en el siglo XIX, el principal medio de transporte entre China y España es el barco. Esta ruta rodea el sur de Asia, atraviesa el mar Rojo y accede al mar Mediterráneo a través del Canal de Suez, llegando a los puertos mediterráneos de España (Barcelona, Valencia, Cartagena, Algeciras, etcétera) y continúa rodeando la península ibérica hacia puertos del norte de Europa como Rotterdam. Esta ruta larga viene a durar 45 días.

Las autoridades chinas están mostrando un enorme interés en abrir y consolidar nuevas rutas que permitan suministrar a su territorio. La nueva iniciativa OBOR (One Belt, One Road) plantea la interconexión de 65 países de Asia, África y Europa a través de dos corredores, uno marítimo y otro terrestre (Parra Pérez, 2017). Desde hace pocos años es posible la conexión por ferrocarril entre la ciudad de Madrid y Yiwu. Esta ruta reduce la distancia con respecto a las rutas marítimas y el tiempo de transporte a algo más de veinte días.

El tren que une Madrid con Yiwu sale de la Unión Europea en la frontera de BrestMalaszewicze, entre Polonia y Bielorrusia, entra en la Unión Euroasiática y llega a China por el paso Dostyk-Alashankou.

Actualmente, uno de los principales escollos de esta ruta es el tránsito por la Unión Euroasiática y en particular, por Rusia. Independientemente de las inclemencias meteorológicas en invierno, debido al bloqueo $\square$ 
político impuesto por Rusia a los productos de la Unión Europea, el tránsito de las mercancías afectadas a través de Rusia se ve dificultado, aunque este país no sea su destino final. A estos problemas se une el hecho de que la mayoría de productos agroalimentarios necesitan de transporte en contenedores refrigerados.

Las exportaciones españolas podrían beneficiarse de unas rutas más cortas si conseguimos estabilidad, tanto en cuanto a tránsito como a regularidad.

\section{Conclusiones}

Las cifras que representan el mercado chino y el incremento del poder de compra de los consumidores hacen que este mercado sea prioritario para las exportaciones futuras de productos agroalimentarios españoles. Aunque el mercado chino presenta en la actualidad una serie de oportunidades en el comercio internacional, no está exento de cierta incertidumbre.

Como hemos visto, en el repaso de las cifras de exportaciones a China de productos agroalimentarios, es previsible que sigamos creciendo en aquellos productos que ya son de interés para la exportación española, como son los de porcino, vinos y aceites (productos de gran potencial de crecimiento), los PAT (chocolate y confitería, pastas, agua mineral, alimentación infantil), y tratar de aumentar las exportaciones de algunas frutas como cítricos o frutos de hueso.

Se identifican algunos sectores que ofrecen oportunidades para las empresas españolas como es el agua embotellada, los zumos, los snacks dulces y salados, las conservas de pescado y la miel, los productos pesqueros, especialmente en los destinos de las áreas costeras de Shanghai y Cantón, además de los productos que ya cuentan con protocolos sanitarios como son algunas frutas (Ofecome en Cantón, 2016 y 2017).

Existen, no obstante, algunas incertidumbres sobre cuestiones que irán definiendo el futuro de las relaciones comerciales con China, de las que hemos comentado en páginas anteriores, entre las que cabe mencionar las cuestiones fitosanitarias, el entorno político y legislativo en China, los programas de incremento de la producción doméstica de alimentos, la nueva ley de seguridad alimentaria y su aplicación a los productos importados o la gestión de los instrumentos de defensa comercial, que puedan llevar a disputas, como las que existen en la actualidad entre EEUU y China, y la evolución de la iniciativa OBOR, entre otros.

Las empresas exportadoras del sector agroalimentario tendrán que valorar el riesgo país y, en su caso, la gran dependencia que puede representar el mercado chino para su negocio, sin olvidar que en el continente asiático hay mercados alternativos que pueden ser también interesantes.

Por su parte, la UE tiene que seguir prestando una gran atención a China, con miras a incrementar las exportaciones al mercado chino, abordando contenciosos de acceso comercial y promocionando en China los alimentos de calidad y seguros de la UE. Del mismo modo, para que se incrementen las exportaciones de productos agroalimentarios españoles a China será necesario seguir avanzando en la negociación de nuevos protocolos sectoriales de acceso al mercado.

La enorme extensión de China y la desigual distribución geográfica y de renta de la población hacen que haya que prestar una gran atención a los modos de distribución comercial de los productos en ese mercado y, de manera particular, a las nuevas formas de venta a $\triangleright$ 
través de las plataformas de comercio electrónico en China.

En definitiva, por su tamaño, por las tasas de crecimiento, por la creciente clase media y por la mayor demanda de productos importados de calidad, China seguirá siendo un mercado estratégico para la exportación de productos agroalimentarios. España, con una oferta variada de productos agroalimentarios, tiene que seguir jugando todas sus bazas para incrementar su presencia en este mercado en los próximos años.

\section{Bibliografía}

[1] ALONSO DÍAZ, A. (2009). «Barreras sanitarias y fitosanitarias en China. Estado de la cuestión». Boletín económico de ICE, n.. 2972, pp. 177-182.

[2] CEXGAN (2018). CEXGAN, buscador de documentos públicos del MAPAMA [en línea]. Madrid: MAPAMA. Disponible en: https:// servicio.magrama.gob.es/cexgan/Publico/ Publico/Buscador.aspx [recuperado: 2018, 26 de enero].

[3] COMISIÓN EUROPEA (2017). Monitoring UE Agri-Food Trade: Development until October 2017 [en línea]. Bruselas: Comisión Europea. Disponible en: https://ec.europa.eu/agriculture/sites/agriculture/files/trade-analysis/ monitoring-agri-food-trade/2017-10_en.pdf [Recuperado: 2018, 26 de enero].

[4] COMISIÓN EUROPEA (2017, junio). Nota de prensa: 100 European geographical indications set to be protected in China [en línea]. Bruselas: Comisión Europea. Disponible en: http://europa.eu/rapid/press-release_IP17-1507_en.htm [Recuperado: 2018, 26 de enero].

[5] COMISIÓN EUROPEA (2018). Registration is now open for the business delegation to accompany Commissioner Phil Hogan to China [en línea]. Bruselas: Comisión Europea. Disponible en: https://ec.europa. eu/info/events/high-level-mission-china-2018may-14_en [Recuperado: 2018, 26 de enero].
[6] DEPARTAMENTO DE ADUANAS E IMPUESTOS ESPECIALES, AEAT (2017). Base de datos de estadísticas del comercio exterior [en línea]. Madrid: MINECO. Disponible en: http://datacomex.comercio.es/ [Recuperado: 2018, 15 de enero].

[7] DGTRADE, COMISIÓN EUROPEA (2018, enero). Overview of FTA and other trade negotiations [en línea]. Bruselas: Comisión Europea. Disponible en: http://trade.ec.europa.eu/doclib/docs/2006/december/tradoc_118238.pdf [Recuperado: 2018, 26 de enero].

[8] LIGHTHIZER, R.;SEKO, H.y MALMSTRÖM, C. (2017). Joint Statement on a Global Level Playing Field [en línea]. Buenos Aires. Disponible en: http://trade.ec.europa.eu/doclib/press/index.cfm?id=1771 [Recuperado: 2018, 26 de enero].

[9] MAPAMA (2017). Autodeclaración por España de la ausencia de influenza aviar altamente patógena (2 de junio de 2017) [en línea]. Madrid: MAPAMA. Disponible en: http://www.mapama.gob.es/es/ganaderia/ temas/sanidad-animal-higiene-ganaderal informe_oie_01_06_2017_tcm7-459026.pdf [Recuperado: 2018, 26 de enero].

[10] MAPAMA (2017). Nota de prensa: «Carlos Cabanas suscribe con las autoridades chinas un Protocolo de exportación de melocotones y ciruelas y un Memorandum de cooperación técnica» [en línea]. Madrid: MAPAMA. Disponible en: http://www.mapama.gob.es/ es/prensa/171120ccabanasfirmaconveniospekin_tcm7-472348_noticia.pdf [Recuperado: 2018, 26 de enero].

[11] NDRC, NATIONAL DEVELOPMENT AND REFORM COMMISSION, PEOPLE'S REPUBLIC OF CHINA (2016, diciembre). The 13th five-year plan for economic and social development of the People's Republic of China (2016-2020) [en línea]. Pekín: Central Compilation \& translation press. Disponible en: http://en.ndrc.gov.cn/newsrelease/201612/ P020161207645765233498.pdf [Recuperado: 2018, 30 de enero].

[12] O'DONOVAN, R. (ed.) (2018). «French beef exports", Agrafacts n.. $02-18,4$ pp.

[13] OCDE-FAO (2017). OCDE-FAO Perspectivas Agrícolas 2017-2026 [en línea] París: $D$ 
Éditions OCDE. Disponible en: $h t t p: / / w w w$. fao.org/3/a-i7465s.pdf [Recuperado: 2018, 26 de enero ].

[14] OFECOME EN CANTÓN (2016). El Mercado de productos de Alimentación emergentes en China. Estudios de Mercado. Cantón: Oficina Económica y Comercial de la Embajada de España en Cantón-ICEX.

[15] OFECOME EN CANTÓN (2017). El Mercado del pescado y del marisco en China. Noviembre 2017. Estudios de Mercado. Cantón: Oficina Económica y Comercial de la Embajada de España en Cantón-ICEX.

[16] OFECOME EN CANTÓN (2017). El Mercado de la fruta en China. Agosto 2017. Estudios de Mercado. Cantón: Oficina Económica y Comercial de la Embajada de España en Cantón-ICEX.

[17] OFECOME EN PEKÍN (2017). Informe económico y comercial. China 2017 [en línea] Pekín: Oficina Económica y Comercial de España en Pekín-ICEX. Disponible en: https://www.icex. es/icex/es/navegacion-principal/todos-nuestros-servicios/informacion-de-mercados/ estudios-de-mercados-y-otros-documentos-de-comercio-exterior/DOC2017692549. html [Recuperado: 2018, 26 de enero].

[18] OMC (2016). Examen de las políticas comerciales. Informe de la secretaría. China. (WT/TPR/S/342), [en línea]. Ginebra: OMC. Disponible en: https://www.wto.org/spanish/ tratop_s/tpr_s/s342_s.pdf [Recuperado: 2018, 26 de enero].

[19] OMC (2017). Notificación G/TBT/N/CHN/1209 $A D D 1$ [en línea]. Ginebra: OMC. Disponible en: $h$ ttps://docs.wto.org/dol2fe/Pages/FE_ Search/FE_S_S009-DP.aspx?language $=E \&-$ CatalogueldList $=238926,238923,238922$, $238924,238925,238943,238944,238942$, 238941,238938\&CurrentCatalogueldIndex= 8\&FullTextHash $=371857150 \&$ HasEnglish Record $=$ True \&HasFrenchRecord $=$ False \&Has
SpanishRecord=False [Recuperado: 2018, 26 de enero].

[20] OMC (2017). Ayuda interna para los productores agropecuarios DS 511 [en línea]. Ginebra: OMC. Disponible en: https://www.wto.org/spanish/tratop_s/dispu_s/cases_s/ds511_s.htm [Recuperado: 2018, 26 de enero].

[21] OMC (2017). Contingentes arancelarios aplicables a determinados productos agroalimentarios DS 517 [en línea]. Ginebra: OMC. Disponible en: https://www.wto.org/spanish/tratop_s/dispu_s/cases_s/ds517_s.htm [Recuperado: 2018, 26 de enero].

[22] OMC (2017). Medidas en materia de derechos antidumping compensatorios sobre los productos de pollo de engorde procedentes de los Estados Unidos DS 427 [en línea]. Ginebra: OMC. Disponible en: https://www. wto.org/spanish/tratop_s/dispu_s/cases_s/ ds427_s.htm [Recuperado: 2018, 26 de enero].

[23] OMC (2017). Notificación G/TBT/NCHN/1209 «Measures for the Administration of Certificates Attached to Foods Exported to China (Draft) (4 page(s), in Chinese)», [en línea]. Ginebra: OMC. Disponible en: https:// docs.wto.org/dol2fe/pages/FE_Search/ $F E \_S \_S 009-D P$.aspx? language $=E \& H a s-$ EnglishRecord $=$ True \& HasFrenchRecord $=-$ True\&HasSpanishRecord $=$ True\&CatalogueldList $=236989 \&$ CurrentCatalogueldIndex $=0 \&$ FullTextHash=371857150 [Recuperado: 2018, 26 de enero].

[24] PARRA PÉREZ, A. (2017, noviembre). "OBOR: las 5 claves de la mayor iniciativa de infraestructuras mundial liderada por China». Instituto Español de Estudios Estratégicos, 14 de noviembre de 2017, Documento de Opinión 113/2017, pp.19. Disponible en: $h$ ttp:// www.ieee.es/Galerias/fichero/docs_opinion/2017/DIEEEO113-2017_OBOR_China_ AguedaParra.pdf [Recuperado: 2018, 30 de enero]. 
